\title{
Recent Advances in the Chemistry of Clusters and Inorganic Polymers of Alkali and Alkaline Earth Metal Compounds
}

\author{
Katharina M. Fromm*
}

\begin{abstract}
This contribution gives an overview on the different subjects treated in our group during the last four years. First, the concept of cutting out structural fragments from a solid-state structure will be explained on behalf of $\mathrm{Bal}_{2}$. Oxygen donor ligands, used as chemical scissors on $\mathrm{Bal}_{2}$, enabled three-, two-, one- and zero-dimensional derived compounds to be obtained depending on their size and concentration. Thus, a structural genealogy tree for $\mathrm{Bal}_{2}$ can be established. A second section deals with the supramolecular approach for the synthesis of different dimensional polymer structures derived from alkaline earth metal iodides, and based on the combination of metal ion coordination with hydrogen bonding between the cationic complexes and their anions. Under certain circumstances, rules can be established for the prediction of the dimensionality of a given compound, thus contributing to the problem of structure prediction in crystal engineering. A third part describes a new synthetic pathway for generating homometallic alkaline earth metal clusters as well as group 1 and 2 mixed metal clusters as potential precursors for oxide materials. Finally, some physical properties of these compounds are described qualitatively in order to show the wide spectrum of possibilities and potential applications for the chemistry in this field.
\end{abstract}

Keywords: Alkali metals · Alkaline earth metals · Clusters · Inorganic polymers · Oxide materials

\section{Introduction}

We became interested in the non-aqueous chemistry of alkali and alkaline earth metal elements for several reasons: i) the chemistry of alkali and alkaline earth metal compounds in water can best be described as ionic whereas not much was known about their behavior in more organic solvents; ii) alkali and alkaline earth metal clusters - in the sense of aggregates or cage compounds - were observed as by-products in metallation reactions in organic chemistry which encouraged us to make such compounds on purpose; iii) we wanted to know whether there is an analogy in the clusters of group 1 and 2 , and transition metal clusters, i.e. of

\footnotetext{
${ }^{\star}$ Correspondence: Dr. K.M. Fromm University of Geneva Sciences II

30, Quai Ernest Ansermet

$\mathrm{CH}-1211$ Geneva 4

Tel. : +41227026032

Fax: +41227026830

E-Mail: katharina.fromm@chiam.unige.ch

www.unige.ch/chiam/fromm
}

group 11; iv) concerning the 'covalent' polymers, the principle of cutting out structural fragments from a solid-state structure with chemical scissors was to be tested; and v) we wanted to contribute to the problem of structure prediction in the case of supramolecular polymers. Applications for such alkali and alkaline earth metal compounds can be found in many fields, such as metallation reactions and superbases in organic chemistry, biomineralization as far as biology is concerned, or precursors for superconductors or other oxide materials required for physical applications. For the latter, thin films of such materials are currently in the focus of research, and therefore we aimed at the synthesis of precursors for thin film synthesis methods such as sol-gel or chemical vapor deposition (CVD).

This article will review the different research subjects in our group, starting with the inorganic 'covalent' polymers, followed by the supramolecular ones, and ending with a survey of our cluster compounds before presenting conclusions about the properties and some potential applications.

\section{Results and Discussion}

\subsection{Inorganic 'Covalent' Polymers}

The aim of this part of the project consists in the principle of cutting out structural fragments from a three-dimensional compound, using chemical scissors and by maintaining parts of the initial structure [1]. A good starting material is for instance $\mathrm{BaI}_{2}$, which possesses in the solid state a $\mathrm{PbCl}_{2}$-type structure, with the alkaline earth metal ion surrounded by nine iodide ions in form of a distorted, tri-capped trigonal prism (Fig. 1a). This leads to very different $\mathrm{Ba}-\mathrm{I}$ distances, seven of which fall between 3.3 and $3.6 \AA$, and the other two are approximately $4.1 \AA$ long. The idea was to use chemical scissors in order to 'cut' along the longest bonds in the structure and to cut out structural fragments successively. Indeed, with $\mathrm{H}_{2} \mathrm{O}$ acting as chemical scissor on $\mathrm{BaI}_{2}$, the three-dimensional compound $\left[\mathrm{BaI}_{2}\left(\mu_{2}-\mathrm{H}_{2} \mathrm{O}\right)_{2}\right]$ can be isolated (Fig. 1b). Compared to $\mathrm{BaI}_{2}$, the longest $\mathrm{Ba}-\mathrm{I}$ contacts are cut, the trigonal prism of iodide around the cation is maintained, 
whereas the three capping anions are replaced by four $\mu_{2}$-bridging water molecules. The remaining $\mathrm{Ba}-\mathrm{I}$ contacts are the shorter ones and are found between 3.3 and $3.6 \AA$. Upon substitution of one of the two bridging water molecules by a sterically more demanding oxygen donor ligand like acetone $\left(\mathrm{CH}_{3}\right)_{2} \mathrm{CO}$ to yield $\left[\mathrm{BaI}_{2}\left(\mu_{2}-\right.\right.$ $\left.\left.\mathrm{H}_{2} \mathrm{O}\right)\left\{\left(\mathrm{CH}_{3}\right)_{2} \mathrm{CO}\right\}\right]$, a two-dimensional structure is obtained with the acetone ligand in a terminal position (Fig. 1c). In fact, the bulky $\mathrm{CH}_{3}$ groups allow the layers to be separated from each other. The trigonal prismatic arrangement of the six iodide ions around barium is maintained.

Using a sterically more demanding donor ligand like THF, two derivatives of $\mathrm{BaI}_{2}$ can be obtained depending on the quantity of chemical scissors used. With three THF-molecules per $\mathrm{BaI}_{2}$ unit, a onedimensional polymer $\left[\mathrm{BaI}_{2}(\mathrm{thf})_{3}\right]$ is obtained, in which only four $\mathrm{Ba}-\mathrm{I}$ bonds are maintained, yielding a zigzag chain motif (Fig. 1d). The remaining coordination sites on the cation are filled with the bulky THF ligands to lead to a coordination number of seven for barium. Two more $\mathrm{Ba}-\mathrm{I}$ bonds can be cut by adding more THF to yield the zero-dimensional $\left[\mathrm{BaI}_{2}(\mathrm{thf})_{5}\right]$, forming a pentagonal bipyramidal structure with the anions in axial positions (Fig. 1e). The Ba-I bonds become shorter as their number per cation as well as the coordination numbers of $\mathrm{Ba}$ and I decrease, to reach $3.374 \AA$, which is consistent if not shorter than the sum of ionic Shannon radii.

It was thus possible to establish a structural genealogy tree for $\mathrm{BaI}_{2}$ which could also be transferred to $\mathrm{SrI}_{2}$ and $\mathrm{Ba}(\mathrm{OTf})_{2}$ $\left(\mathrm{OTf}=\mathrm{CF}_{3} \mathrm{SO}_{3}{ }^{-}\right)$[2]. We are now investigating other binary compounds (also of transition metals and lanthanides) in which very different bond lengths are observed, in order to proceed similarly. This is of interest as such low-dimensional compounds possess an intrinsic anisotropy, which can be fundamental for the expression of their physical properties.

In the case of alkali metal iodides presenting the same M-I bonds in all directions, crown ethers were used to apply our strategy of cutting out fragments from a solid-state structure. This led to the isolation of molecular species [NaC(DB18C6)I(L)], L $=$ THF, 1, 3-dioxolane, in which the sodium cations are coordinated in an asymmetric fashion [3].



Fig. 1. Structural genealogy tree of $\mathrm{Bal}_{2}$ 


\subsection{Supramolecular Inorganic Polymers}

In this part, the interest focuses on the formation of different dimensional polymer structures obtained by the combination of two binding modes: firstly the metal ion coordination, and secondly the hydrogen bonding. The aim of this project is to contribute to the field of structure prediction, or, at least, the prediction of the dimensionality of a compound in the solid state. Some first experiments led to the conclusion that it is only possible to predict interactions between complex cations, the counter ions and solvent molecules under very restricted conditions [4]. For instance, the compound of the general formula trans- $\left[\mathrm{Ca}(\mathrm{L})_{4}\right.$ $\left.\left(\mathrm{H}_{2} \mathrm{O}\right)_{2}\right] \mathrm{I}_{2}$ does not form similar solid-state structures even when different ligands of $\mathrm{L}$ with similar size, and the same donor atoms are used [5]. Thus, the compound in which $\mathrm{L}=\mathrm{THF}$ forms a two-dimensional network via hydrogen bonds, whereas for $\mathrm{L}=$ ethyl acetate $\left(\mathrm{CH}_{3} \mathrm{COOC}_{2} \mathrm{H}_{5}\right)$, one-dimensional chains are observed. These, together with other results, lead us to fix several conditions under which at least the dimensionality of a compound can be predicted. The following conditions are required in the case of structures of supramolecular polymers of alkaline earth metal iodides: i) the cations form complexes charged $2+$ with polyether ligands and water molecules, ii) the counterions, charged 1-, are the only H-bond acceptors, here two iodides per complex cation, iii) the water ligands, if several, are arranged in vicinal positions, iv) only the water molecules are involved in hydrogen bonding, and $v$ ) each hydrogen of all water molecules forms a single hydrogen bond to iodide, except when two hydrogen atoms of the same water molecule bind to the same iodide [6]. So, the only variable is the bridging functionality of iodide and the number of water ligands per cationic complex. It was found that under these conditions, the number of water molecules coordinated to the alkaline earth metal cation, directs the dimensionality of the final compound. Thus, a compound

Fig. 2. Examples of homometallic alkaline earth metal clusters as precursors for sol-gels with one water molecule, like [Ba(triglyme $\left.)_{2}\left(\mathrm{H}_{2} \mathrm{O}\right)\right] \mathrm{I}_{2}$ has a zero-dimensional structure, one with two water molecules forms a one-dimensional chain, i.e. [Ca(diglyme $\left.)_{2}\left(\mathrm{H}_{2} \mathrm{O}\right)_{2}\right] \mathrm{I}_{2}$, three water molecules present will give a two-dimensional double-layer as in $\left[\mathrm{Ba}(\text { diglyme })_{2}\left(\mathrm{H}_{2} \mathrm{O}\right)_{3}\right] \mathrm{I}_{2}$, and four water molecules bonded to the cation will lead to a three-dimensional compound, i.e. $[\mathrm{Ca}$ (triglyme $\left.)\left(\mathrm{H}_{2} \mathrm{O}\right)_{4}\right] \mathrm{I}_{2}$ or $\left[\mathrm{Ca}(\mathrm{dme})_{2}\right.$ $\left.\left(\mathrm{H}_{2} \mathrm{O}\right)_{4}\right]_{2}$.

We are now investigating how this concept can be generalized for other metal ions, ligands and anions in order to contribute to this important field of fundamental research [7].

\subsection{Clusters of Alkali and Alkaline Earth Metals}

Looking for an analogy to transition metal clusters (in this case, clusters are defined as aggregates without necessarily metal-metal bonds), the following general reaction scheme for obtaining alkaline earth metal clusters was applied: with $\mathrm{MX}_{2}$ being an alkaline earth metal iodide, LiOR being either the hydroxide or $\mathrm{LiO}^{t} \mathrm{Bu}$, and $\mathrm{L}$ an oxygen donor ligand like THF.

Using $\mathrm{CaI}_{2}$ under the above conditions, we were able to isolate the largest Ca-cluster so far, $\mathrm{Li}\left[\mathrm{Ca}_{7} \mathrm{I}_{6}\left(\mu_{3}-\mathrm{OH}\right)_{8}(\mathrm{thf})_{12}\right]_{2}\left(\mu_{2}-\right.$ $\mathrm{I})(\mathrm{THF})_{n}$, with a unique structure of two double-hetero-cubanes linked together via hydrogen bonds to a central iodide, yielding a dumb-bell-like cluster of fourteen calcium ions (Fig. 2a) [8]. The cluster is made up of OH-bridged $\mathrm{Ca}_{3}$-triangles, and such a building block could be isolated when using $\mathrm{SrI}_{2}$ as the starting material under similar conditions to yield $\left[\mathrm{Sr}_{3} \mathrm{I}_{3}\left(\mu_{3^{-}}\right.\right.$ $\left.\mathrm{OH})_{2}(\text { thf })_{9}\right] \mathrm{I}$ (Fig. 2b) [9]. This seems to be a fundamental unit for the construction of higher aggregates, since most of the alkaline earth metal clusters form polyhedra or sheet structures in which triangles of alkali metal ions are fused together.

These two homometallic alkaline earth metal clusters are not volatile, and can thus not be used as CVD (chemical vapor depo-

$$
n \mathrm{MX}_{2}+\mathrm{n}^{n} \mathrm{BuLi}+\mathrm{nLiOR} \underset{\frac{-\left\{[\mathrm{LiX}]\left[{ }^{n} \mathrm{BuLi}\right]\right\}_{\mathrm{n}}}{+ \text { Ligand L }}}{\longrightarrow}
$$

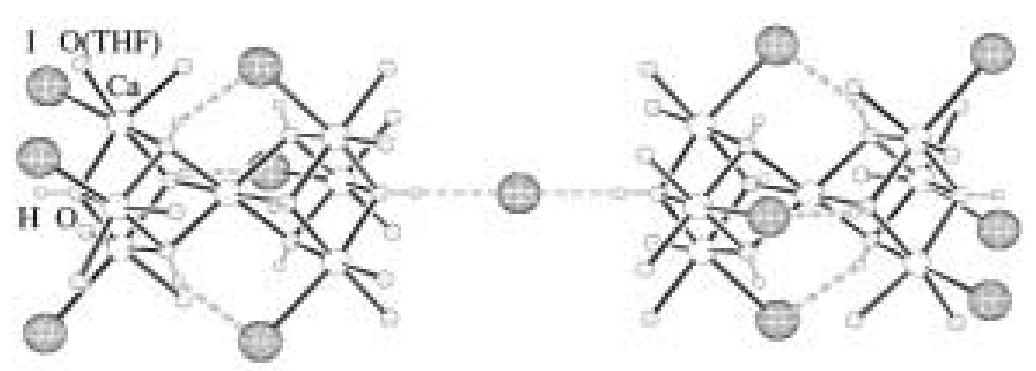

a) Unigae structure of the $\mathrm{Ca}_{14}$-cluster

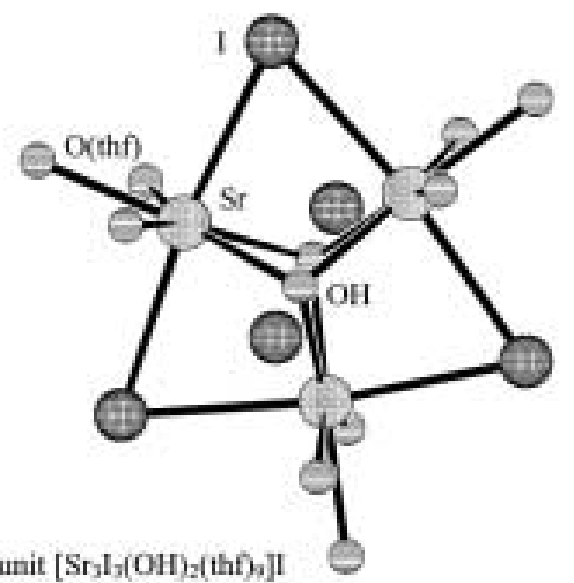

b) Building block $\mathrm{M}_{3}$-unit $\left[\mathrm{Sr}_{3} \mathrm{I}_{3}(\mathrm{OH})_{2}\right.$ (thf $\left.f_{3}\right] \mathrm{I}$ 
sition) precursors. However, they form extremely stable sols in THF upon hydrolysis with, in the case of the calcium compound, a particle size of $100 \mathrm{~nm}$ and a particle composition of $\mathrm{Ca}(\mathrm{OH})_{2}\left(\mathrm{H}_{2} \mathrm{O}\right)_{n}$ which can be used to synthesize thin films of halide-free $\mathrm{CaO}$. In order to introduce volatility, we aimed to replace $\mathrm{LiOH}$ by $\mathrm{LiO}^{t} \mathrm{Bu}$ which is volatile. Under the above reaction conditions and with $\mathrm{CaI}_{2}$ as starting material, only a homometallic lithium cluster $\left[\mathrm{Li}_{4}\left(\mu_{3}-\right.\right.$ $\left.\left.\mathrm{O}^{t} \mathrm{Bu}\right)_{3}(\mathrm{thf})_{4} \mathrm{I}\right]$ with a distorted cubane structure was obtained [9]. With $\mathrm{SrI}_{2}$ and $\mathrm{BaI}_{2}$, the mixed metal clusters $\left[\mathrm{IM}\left(\mathrm{O}^{t-}\right.\right.$ $\left.\mathrm{Bu})_{4}\{\mathrm{Li}(\mathrm{thf})\}_{4}\left(\mu_{4}-\mathrm{OH}\right)\right], \mathrm{M}=\mathrm{Sr}, \mathrm{Ba}$, were isolated (Fig. 3a and b) [9][10]. Calculating the bond valence sums for $\mathrm{Sr}$ and $\mathrm{Ba}$ in each case, one has to take into account the $\mathrm{Sr}-\mathrm{O}(\mathrm{OH})$ contact in addition to the four $\mathrm{Sr}-\mathrm{O}\left(\mathrm{O}^{t} \mathrm{Bu}\right)$ and the $\mathrm{Sr}-\mathrm{I}$ bonds to coordinate the cation to satisfaction. This is not necessary for the Ba cation, so that the coordination number for $\mathrm{Sr}$ in the $\mathrm{Sr}$-compound is six, whereas it is five for $\mathrm{Ba}$ in the heavier analogue. This is expressed in the much more compressed and flat cluster core in the Sr-cluster compared to the barium one. Another difference is the rather good volatility of the barium compound as observed by the mass peak in the electronic impact mass spectrum, whereas for the Sr-compound, only fragments of the structure can be detected under the same conditions. We were thus able to synthesize a new precursor for halide- and carbonatefree barium oxide.

Recently, we started investigating the structures of alkali metallated calixarenes, as they are used as intermediates in the synthesis of transition metal derivatives of calixarenes, which are studied in the context of metal ion adsorption on an oxide surface [11]. Calixarenes are also used to model bi- ological systems, i.e. the alkali metal ion transport antibiotics in cell membranes.

\subsection{Applications (Scheme)}

Among the above results, some compounds were found to exhibit interesting properties. Thus, the one-dimensional $\left.[\mathrm{Ca} \text { (diglyme })_{2}\left(\mathrm{H}_{2} \mathrm{O}\right)_{2}\right] \mathrm{I}_{2}$ crystallizes in the polar space group $C \mathrm{c}$, leading to the physical properties of i.e. non-linear optics (NLO) and piezoelectronics. For this compound, we were able to show that it is capable of producing second harmonics when irradiated with a laser. The effect is weaker than in the classically used $\mathrm{KH}_{2} \mathrm{PO}_{4}$, however, good materials for NLO based on inorganic coordination compounds with a long-time resistance against heat and light are the focus of current research for certain applications. The compounds [NaC (DB18C6)I(L)] crystallize in acentric space groups as well, and the crystals are observed to be birefringent under the polarizing microscope.

Since $\left[\mathrm{IBa}\left(\mathrm{O}^{t} \mathrm{Bu}\right)_{4}\{\mathrm{Li}(\text { thf })\}_{4}\left(\mu_{4}-\mathrm{OH}\right)\right]$ $(=$ 'BaLi4') is volatile, it seemed to us a suitable precursor for barium oxide. Solution studies of the cluster, especially by NMR, revealed that the cluster retains its structure in solution, except for a fast exchange of THF ligands in $\mathrm{d}_{8}$-THF. We then brought the $\mathrm{BaLi} 4$ cluster onto a substrate of $\mathrm{SrTiO}_{3}$ via a dip-coating method consisting of slowly withdrawing the substrate from the solution and letting the solvent evaporate. At room temperature, the partially crystalline material was shown to be indeed the BaLi4 cluster. After thermal treatment as used in the synthesis of superconductors, only $\mathrm{BaO}$ was left on the surface, thus proving the possibility to use BaLi4 as precursor for CVD of metal oxides. The two pure alkaline earth metal clusters were not only shown to form sols on hydrolysis, but also the corresponding carbonates on reaction with air. We now investigate the formation of $\mathrm{CaCO}_{3}$ in the context of biomineralization.

\section{Acknowledgement}

I am indebted to Prof. A.F. Williams for having accepted me in his group and for giving me the opportunity to do my own research. I wish to thank both, Prof. A.F. Williams and Prof. C. Piguet for their most generous support during my habilitation. The Swiss National Foundation is thanked for continuous funding of this research project. K.M.F. and E.D.G. thank the Société Chimique de Genève, the Fonds Firmenich and the Fonds Marc Birkigt for travel grants.

Received: October 3, 2002

Fig. 3. Comparison of the molecular structures of $\left[\mathrm{IM}\left(\mathrm{O}^{t} \mathrm{Bu}\right)_{4}\{\mathrm{Li}(\mathrm{thf})\}_{4}\left(\mu_{4}-\mathrm{OH}\right)\right], \mathrm{M}=\mathrm{Sr}, \mathrm{Ba}$.

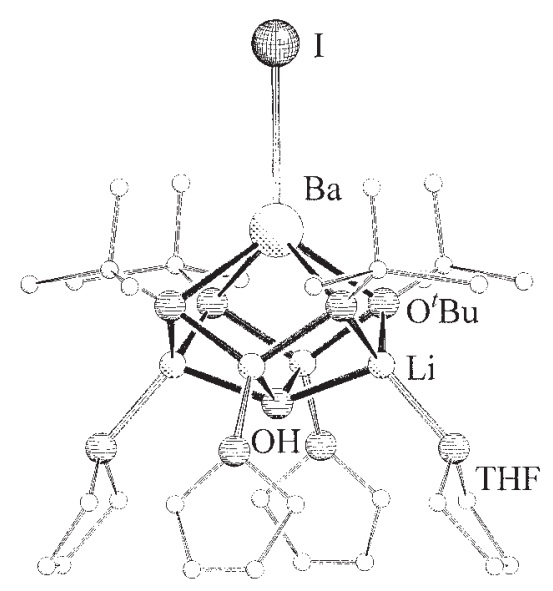

a)

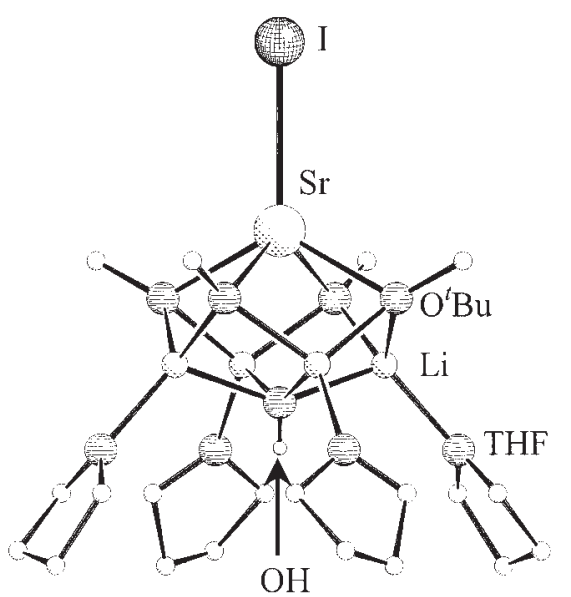

b)
$\mathrm{OH}$ ( 


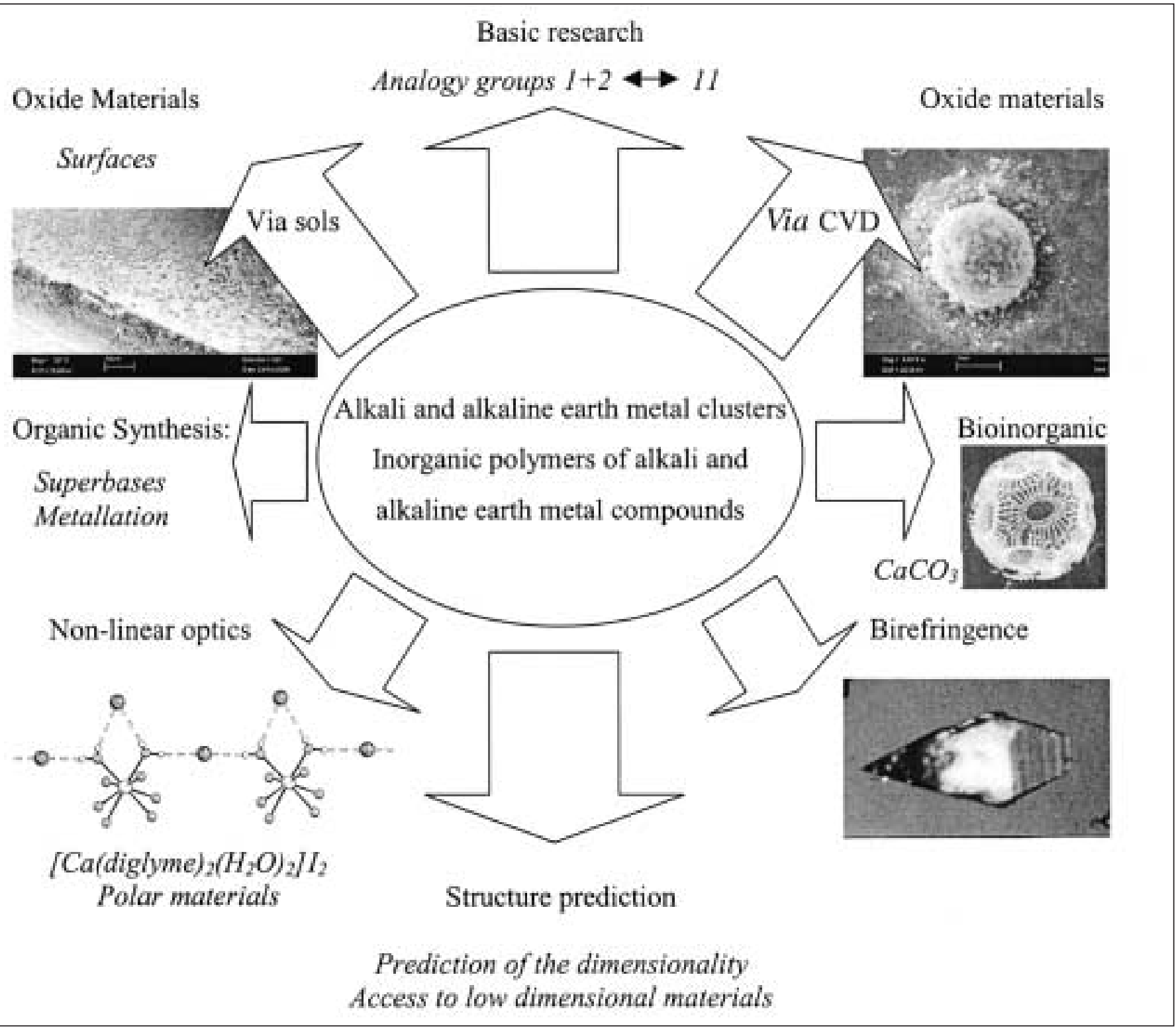

Scheme. Possible applications of group 1 and 2 compounds

[1] K.M. Fromm, Angew. Chem. 1997, 109(24), 2876-2878, Angew. Chem. Int. Ed. Engl. 1997, 36(24), 2799-2801; K.M. Fromm, Cryst. Eng. Comm. 2002, 4(57), 318-322.

[2] K.M. Fromm, G. Bernardinelli, Z. Anorg. Allg. Chem. 2001, 627, 1626-1630.

[3] K.M. Fromm, E.D. Gueneau, J.-P. Rivera, G. Bernardinelli, H. Goesmann, Z. Anorg. Allg. Chem. 2002, 628, 171-178.

[4] K.M. Fromm, G. Bernardinelli, H. Goesmann, Polyhedron 2000, 19, 1783-1789.

[5] K.M. Fromm, G. Bernardinelli, H. Goesmann, M.-J. Mayor-Lopez, J. Weber, Z. Anorg. Allg. Chem. 2000, 626, 1685-1691.

[6] K.M. Fromm, Chem. Eur. J. 2001, 7, 2236-2244.

[7] D.G. Kurth, K.M. Fromm, J.-M. Lehn, Eur. J. Inorg. Chem. 2001, 1523-1526.

[8] K.M. Fromm, Chem. Comm. 1999, 17, $1659-1660$.
[9] K.M. Fromm, E.D. Gueneau, G. Bernardinelli, H. Goesmann, J. Weber, M.-J. Mayor-López, P. Boulet, H. Chermette, accepted for publication in J. Am. Chem. Soc.; K.M. Fromm, E.D. Gueneau, H. Goesmann, G. Bernardinelli, submitted to Helv. Chim. Acta.

[10] K.M. Fromm, E.D. Gueneau, H. Goesmann, Chem. Comm. 2000, 2187-2188.

[11] K.M. Fromm, E.D. Gueneau, H. Goesmann, submitted to Chem. Eur. J.

[12] K.M. Fromm, H. Goesmann, Acta Cryst. Sect. C. 2000, 56(10), 1179-1180. 